\title{
ANÁLISE ESPACIAL DOS PROCESSOS HIDROSSEDIMENTOLÓGICOS NA BACIA DO RIO TAPEROÁ-PB
}

\author{
Irla Gabriele Nunes Henriques ${ }^{(a)}$, Richarde Marques da Silva ${ }^{(b)}$, Leonardo Pereira e Silva $^{(c)}$ \\ (a) Departamento de Geociências/ CCEN/Universidade Federal da Paraíba/Bolsista de Iniciação Científica do \\ CNPq, irlageo10@gmail.com \\ (b) Departamento de Geociências/CCEN/Universidade Federal da Paraíba, richardemarques@yahoo.com.br \\ (c) Programa de Pós-Graduação em Engenharia Civil e Ambiental/CT/Universidade Federal da Paraíba, \\ lpsjampa@gmail.com
}

\section{Eixo: GEOTECNOLOGIAS E MODELAGEM ESPACIAL EM GEOGRAFIA FÍSICA}

\author{
Resumo
}

\begin{abstract}
Este estudo tem como objetivo estimar o escoamento superficial e a produção de sedimentos na bacia do Rio Taperoá. Essa bacia está localizada no semiárido do Estado da Paraíba e possui vegetação característica do bioma Caatinga. Para estimar os processos hidrossedimentológicos foi utilizado o modelo Soil and Water Assessment Tool (SWAT). Neste trabalho foram utilizados dados de precipitação, temperatura e umidade para o período de 1994 a 1999, além de mapa pedológico, de uso e ocupação da terra e o modelo digital de elevação (MDE). Quanto à estimativa de escoamento superficial a maior concentração do escoamento superficial ocorreu na porção sul da bacia, principalmente nas sub-bacias próximas ao exutório, sendo que, a sub-bacia 15 foi aquela com a maior média anual do período estudado e a menor média foi obtida para a sub-bacia 2 . Os resultados evidenciaram que a concentração do escoamento superficial ocorre principalmente nas sub-bacias próximas ao exutório, localizadas ao sul da bacia (sub-bacias 9,11,12 e 15). Quanto à estimativa da produção de sedimentos, pode-se observar que as sub-bacias 1,3 e 8 foram as que mais produziram sedimentos variando de 0,006 a 0,016 ton/ha/ano, e estão localizadas na porção oeste da bacia.
\end{abstract}

Palavras chave: Produção de sedimentos, modelo SWAT, bacia do Rio Taperoá.

\section{Introdução}

A erosão hídrica do solo é um processo físico que ocorre de forma natural, mas é um fenômeno que vem sendo motivo de preocupação em todo o mundo, devido aos impactos que causa aos recursos naturais (FAO, 1993). Esse processo natural pode se tornar intenso pelo o escoamento superficial que é influenciado pela a declividade do terreno e pela ação antrópica. Isso ocorre devido à ação das águas da chuva, as quais provocam a desagregação das partículas do solo, por meio do impacto direto das gotas da chuva com a cobertura pedológica, provocando a ruptura dos agregados do solo (erosão por embate). Com isso, acontece outro processo, que é o transporte das partículas do solo, esse transporte ocorre quando o solo está saturado, ou quando a intensidade da chuva supera a capacidade de infiltração do solo. O que provoca o escoamento superficial do excesso de água e a deposição, ocorrendo quando o material transportado pela erosão se deposita e isso se verifica em áreas mais baixas, podendo ser reservatórios de água (SILVA et al., 2010). 
OS DESAFIOS DA GEOGRAFIA FÍSICA NA FRONTEIRA DO CONHECIMENTO

Instituto de Geociências - Unicamp

Campinas - SP

28 de Junho à 02 de Julho de 2017

O processo erosivo de forma intensa pode provocar problemas como: redução da fertilidade do solo; assoreamento, que leva a diminuição da capacidade de armazenamento de água; poluição das águas; perda de matéria orgânica (BAKKER et al., 2004; CERDAN et al., 2010); aumento do risco de desertificação; risco de formação de sulcos ou voçorocas; destruição de nascentes e a modificação das calhas dos rios, pelo o desmoronamento e pela deposição de sedimento no leito (CARVALHO, 2008). Esses problemas atingem toda a população, podendo levar ao abandono das terras e ao declínio das comunidades rurais (BAKKER et al., 2005).

O solo é o ambiente físico onde ocorre a maioria das atividades humanas. É um recurso natural renovável, mas a sua velocidade de formação é inferior a do processo erosivo. Nas regiões áridas e semiáridas esse fato é ainda mais evidente, pois a taxa de formação de solo é praticamente nula (DESIR e MARIN, 2007).

A região semiárida do Brasil tem como característica a baixa precipitação pluviométrica e a alta taxa de evapotranspiração resultando, em geral, na falta de água para o consumo vegetal, animal e humano (PEREZ-MARIN et al., 2012). A principal atividade econômica da maioria das regiões de semiárido do Brasil é a agricultura familiar e a pecuária extensiva, atividades que contribuem para o desmatamento, determinando áreas que serão suscetíveis à erosão. Corroborando com essa afirmação, Sousa et al. (2007) afirmam que as terras dessa região estão comprometidas com o desmatamento e pela a atividade pecuária extensiva, ações que são danosas a capacidade de resiliência do bioma caatinga. Essas práticas são as responsáveis pelo aparecimento de processos erosivos severos, que desencadeiam o processo de desertificação.

Esse trabalho tem o objetivo de estudar o comportamento dos processos sedimentológicos em uma bacia localizada no semiárido paraibano. Para isso, foi necessária a utilização de modelagem associada à SIG (Sistema de Informações Geográficas), com o modelo mundialmente utilizado, o Soil and Water Assessment Tool (SWAT). Segundo Silva et al. (2014), uma das vantagens de se utilizar esse modelo é a sua capacidade de aplicação em diferentes escalas de bacias hidrográficas, contribuindo para os estudos mais específicos sobre a causa e a consequência da erosão dos solos em escala de bacia hidrográfica localizada no semiárido, pois são áreas que sofrem com alta variabilidade nas precipitações e também com eventos de chuva extrema.

\section{Materiais e Métodos}

\section{Modelo SWAT e dados de entrada}

O modelo utilizado na pesquisa, o Soil and Water Assessment Tool (SWAT) foi desenvolvido por Arnold e Allen (1996), nos EUA em 1996, no Agricultural Research Service e pela Texas A\&M University. Segundo Silva et al. (2013), o SWAT é um modelo hidrossedimentológico, que oferece mecanismos para prever o efeito de diversas ações no solo, como o uso e manejo do solo, a produção 


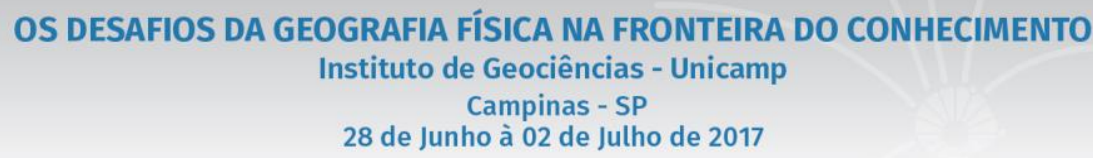

de nutrientes, o uso de pesticidas sobre os recursos hídricos e as perdas de solo. Além de ser um dos modelos mais utilizados no mundo por possuir uma diversidade de parâmetros que controlam os processos do ciclo hidrológico.

É um modelo de base física que é capaz se simular cenários de uso e manejo do solo no ciclo hidrológico, o escoamento superficial e a produção de sedimentos, em diferentes escalas. Para isso, o SWAT divide a bacia hidrográfica em sub-bacias homogêneas, ou seja, possuem o mesmo tipo de solo, cobertura vegetal, topografia e uso do solo, são as denominadas HRUs (Unidades de Resposta Hidrológica).

O SWAT necessita de informações climáticas, de solo, vegetação e uso e manejo do solo, pois utiliza equações que descrevem o ciclo hidrológico.

A equação com base no balanço hídrico é utilizada para estimar o escoamento superficial e a com base na equação MUSLE para estimar a produção de sedimentos. Assim, o balance hídrico é dado pela Eq.1:

$$
S W_{t}=S W+\sum_{t=1}^{t}\left(R_{i}-Q_{i}-E T_{i}-P_{i}-Q R_{i}\right)
$$

Sendo SWt a quantidade final de água no solo, t o tempo (dias), Ri a precipitação do dia (mm), Qi o escoamento superficial no dia $(\mathrm{mm})$, ETi a evapotranspiração no dia $(\mathrm{mm})$, Pi a percolação $(\mathrm{mm})$, ou seja a quantidade de água presente na zona vadosa do solo no dia, e por fim o Qi o fluxo de retorno $(\mathrm{mm})$.

Para estimar a produção de sedimentos, o modelo utiliza a equação proposta por Williams (1975), a Equação Universal de Perda do Solo Modificada (MUSLE), onde é substituído o fator de erosividade das chuvas por um fator de escoamento superficial presente na Equação Universal de Perda de Solo (USLE). Então a equação é dada por:

$$
Y=11,8\left(Q_{\text {surf }} \cdot q_{\text {peak }} \cdot \text { area }_{h r u}\right)^{0,56} \cdot K_{U S L E} \cdot L S_{U S L E} \cdot C_{U S L E} \cdot P_{U S L E} \cdot C F R G
$$

Sendo Y a produção de sedimentos (t), Qsurf o volume do escoamento superficial (mm/ha), qpeak o pico de escoamento superficial $\left(\mathrm{m}^{3} / \mathrm{s}\right)$, areahru a área da unidade de resposta hidrológica (ha), KUSLE o fator erodibilidade do solo, CUSLE o fator de uso e manejo do solo, PUSLE o fator de práticas conservacionistas, LSUSLE o fator de topografia e CFRG o fator que considera o afloramento de rocha na área (DANTAS et al., 2015).

Para essa pesquisa foi necessário o uso de dados cartográficos e tabulares com a finalidade da criação de um banco de dados com as características da bacia do Rio Taperoá, para associá-la ao banco de 
XVII Simpósio Brasileiro

de Geografia Fisica Aplicada

I Congresso Nacional

de Geografia Física

\section{OS DESAFIOS DA GEOGRAFIA FÍSICA NA FRONTEIRA DO CONHECIMENTO \\ Instituto de Geociências - Unicamp \\ Campinas - SP \\ 28 de Junho à 02 de Julho de 2017}

dados do modelo. O período utilizado foi de 1994 a 1999 de dados de precipitação coletado de 12 postos descritos na Tabela I. O período de simulação também foi de 1994 a 1999, mas os dois primeiros anos foram utilizados para o aquecimento do modelo.

Para o mapeamento do solo foi utilizado uma imagem do satélite Landsat 5/TM, do dia 18 de Junho do ano de 1990. Essa imagem foi obtida do site do Instituto Nacional de Pesquisas Espaciais-INPE. As classes de uso do solo foram obtidas através da classificação de imagens orbitais. Para este estudo foram determinadas quatro classes de uso da terra para a bacia, são elas: (a) Água, (b) Vegetação Arbustiva, (c) Vegetação Herbácea e (d) Solo exposto/Agricultura. As imagens foram classificadas usando o método supervisionado a partir do classificador de Máxima Verossimilhança. A Figura 3 mostra a distribuição espacial das classes de uso do solo que foram identificadas na imagem. A validação das classes de uso da terra foi determinada com base em visitas de campo na área de estudo.

Tabela I. Localização geográfica dos postos pluviométricos utilizados neste estudo

\begin{tabular}{|c|c|c|c|c|c|}
\hline ID & Postos Pluviométricos & Código do posto & Longitude $(\mathbf{W})$ & Latitude (S) & Altitude $(\mathbf{m})$ \\
\hline Posto 1 & Taperoá & $\mathbf{3 8 4 6 4 3 4}$ & $\mathbf{- 3 6 , 8 3}$ & $\mathbf{- 7 , 2 0}$ & $\mathbf{5 0 0}$ \\
\hline Posto 2 & Santo André & $\mathbf{3 8 4 6 4 7 5}$ & $\mathbf{- 3 6 , 6 0}$ & $-\mathbf{7 , 2 1}$ & $\mathbf{4 7 0}$ \\
\hline Posto 3 & Santa Tereza & $\mathbf{3 8 4 5 1 1 3}$ & $\mathbf{- 3 6 , 4 1}$ & $-\mathbf{7 , 1 1}$ & $\mathbf{5 0 0}$ \\
\hline Posto 4 & Soledade & $\mathbf{3 8 4 7 1 2 8}$ & $\mathbf{- 3 6 , 3 6}$ & $-\mathbf{7 , 0 6}$ & $\mathbf{5 6 0}$ \\
\hline Posto 5 & Serra Branca & $\mathbf{3 8 4 6 9 6 9}$ & $\mathbf{- 3 6 , 6 6}$ & $-\mathbf{7 , 4 8}$ & $\mathbf{4 5 0}$ \\
\hline Posto 6 & São José Dos Cordeiros & $\mathbf{3 8 4 6 7 3 9}$ & $\mathbf{- 3 6 , 8 1}$ & $-\mathbf{7 , 3 8}$ & $\mathbf{6 1 0}$ \\
\hline Posto 7 & Pocinhos & $\mathbf{3 8 4 7 1 8 8}$ & $\mathbf{- 3 6 , 0 6}$ & $\mathbf{- 7 , 0 6}$ & $\mathbf{6 2 4}$ \\
\hline Posto 8 & Juazeirinho & $\mathbf{3 8 4 6 1 8 5}$ & $\mathbf{- 3 6 , 5 8}$ & $-\mathbf{7 , 0 6}$ & $\mathbf{5 7 0}$ \\
\hline Posto 9 & Gurjão & $\mathbf{3 8 4 7 5 0 5}$ & $\mathbf{- 3 6 , 4 8}$ & $-\mathbf{7 , 2 6}$ & $\mathbf{4 8 0}$ \\
\hline Posto 10 & Coxixola & $\mathbf{3 8 5 6 2 7 8}$ & $\mathbf{- 3 6 , 6 1}$ & $-\mathbf{- 7 , 6 1}$ & $\mathbf{4 6 5}$ \\
\hline Posto 11 & Fazenda Bananeiras & $\mathbf{3 8 5 6 0 0 8}$ & $\mathbf{- 3 6 , 9 6}$ & $\mathbf{- 7 , 5 1}$ & $\mathbf{7 0 0}$ \\
\hline Posto 12 & Desterro & $\mathbf{3 8 4 5 5 3 3}$ & $\mathbf{- 3 7 , 1 0}$ & $-\mathbf{- 7 , 2 8}$ & $\mathbf{5 9 0}$ \\
\hline
\end{tabular}

Como o modelo possui seu próprio banco de dados, com parâmetros que influenciam no escoamento superficial, então foi feito uma associação das classes de uso do solo encontradas na bacia com as que existem no banco de dados do SWAT.

\section{Aplicação e calibração do Modelo SWAT}

As etapas para a aplicação do modelo são: (a) delimitação da bacia hidrográfica a partir do MDE, (b) definição das HRUs com base nos mapas de uso e ocupação do solo e tipo de solo, (c) caracterização da bacia com a inserção dos dados climáticos e (d) executar o modelo. Concluídas essas etapas, o modelo determinou a divisão da bacia do Rio Taperoá em 15 sub-bacias. A partir dessa etapa foram calculados os processos de escoamento superficial e a produção de sedimentos para cada sub-bacia.

\section{Localização e Caracterização da Área de Estudo}

Segundo Dantas et al. (2015), a bacia do Rio Taperoá está localizada na região do semiárido paraibano, na Mesorregião da Borborema, entre as coordenadas $36^{\circ} 0^{\prime} 0^{\prime \prime} \mathrm{W}, 37^{\circ} 15^{\prime} 0^{\prime \prime} \mathrm{W}$ e $6^{\circ} 45^{\prime} 0^{\prime \prime} \mathrm{S}, 7^{\circ} 45^{\prime} 0^{\prime \prime} \mathrm{S}$, abrangendo uma área de $5.658 \mathrm{~km}^{2}$ (Figura 1). Essa bacia foi escolhida para esse estudo, por possuir 
XVII Simpósio Brasileiro

de Geografia Fisica Aplicada

I Congresso Nacional

de Geografia Física

\section{OS DESAFIOS DA GEOGRAFIA FÍSICA NA FRONTEIRA DO CONHECIMENTO Instituto de Geociências - Unicamp \\ Campinas - SP \\ 28 de Junho à 02 de Julho de 2017}

um vasto acervo de dados hidrossedimentológicos e por representar bem uma área do semiárido brasileiro. O principal rio da bacia é o rio Taperoá, que tem sua nascente na Serra do Teixeira e deságua no Rio Paraíba, açude Boqueirão, sendo um dos principais rios do estado, pois o açude Boqueirão a abastece cidades como Campina Grande e Monteiro.

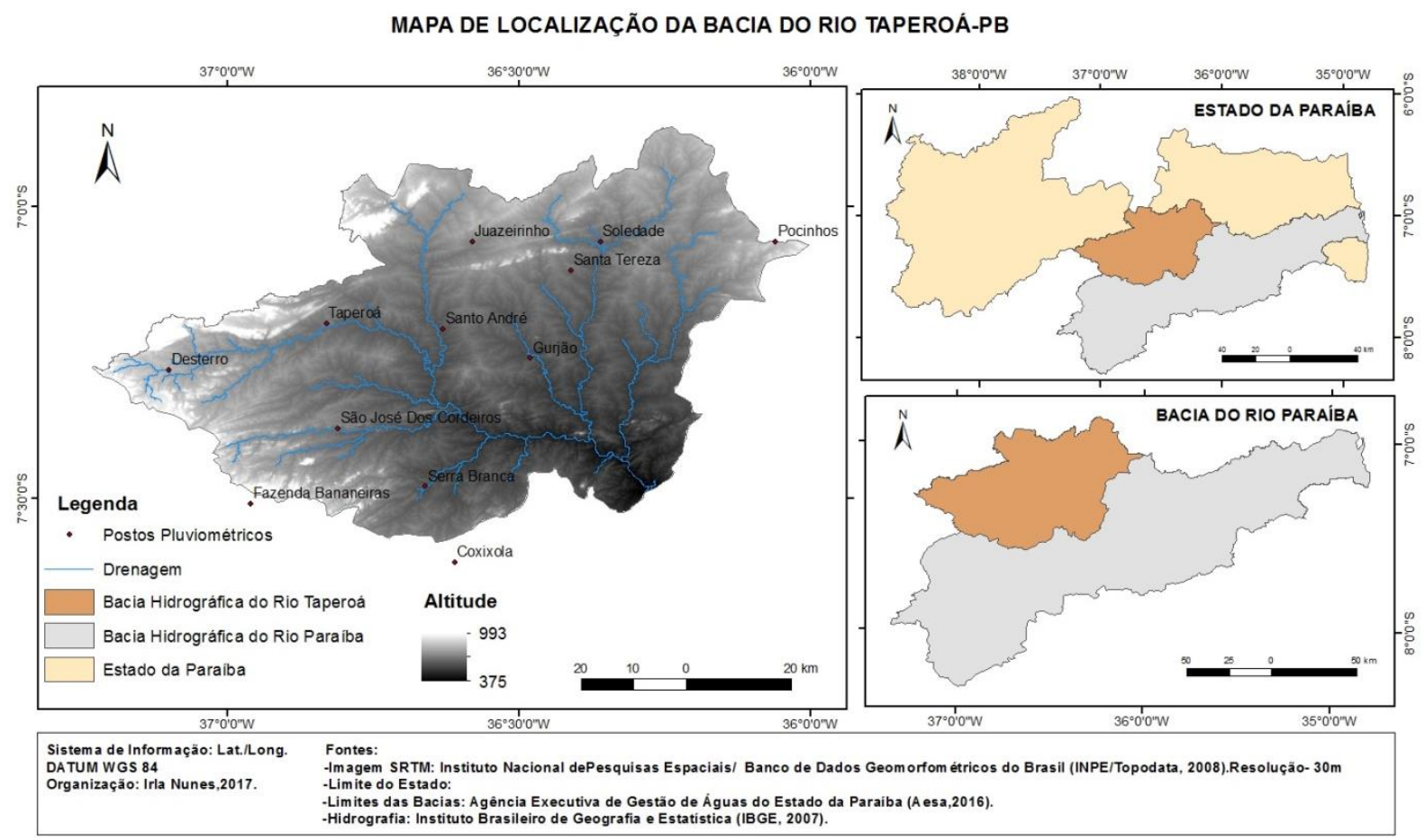

Figura 1 - Localização da bacia do Rio Taperoá, no Estado da Paraíba.

A bacia do Rio Paraíba pertence ao Bioma Caatinga, que apresenta como características marcantes, a irregularidade pluviométrica e a existências de duas estações bem definidas, a estação chuvosa e a estação seca (ANDRADE, 2008).

De acordo com Mendonça e Danni-Oliveira (2007) essa bacia está localizada na região de clima tropical equatorial do tipo $2 \mathrm{~d}$, com concentração da chuva em 4 meses no ano (de Janeiro à Abril), as médias pluviométricas são baixas em média $400 \mathrm{~mm} /$ ano e as temperaturas médias superam $28{ }^{\circ} \mathrm{C}$. A vegetação que predomina nessa bacia é segundo Souza et al. (2004) do tipo caatinga, de porte baixo, e culturas do tipo palma forrageira, agave e algodão e temporariamente feijão e milho.

Segundo o levantamento de solos da Agência Executiva de Gestão de Águas do Estado da Paraíba (AESA), a bacia do Rio Taperoá possui nove tipos de solos, sendo 34,68\% da bacia é composta de Neossolo Litólico, 25,72\% de Luvissolo Crômico, 16,20\% de Planossolo, 13,95\% de Neossolo Regolítico, 5,10\% de Neossolo Flúvico, 2,33\% de Vertissolo, 1,27\% de Cambissolo e 0,02\% de Latossolo, além de $0,74 \%$ de afloramentos rochosos (Figura 2). 
Tipos de Solos da Bacia do Rio Taperoá-PB

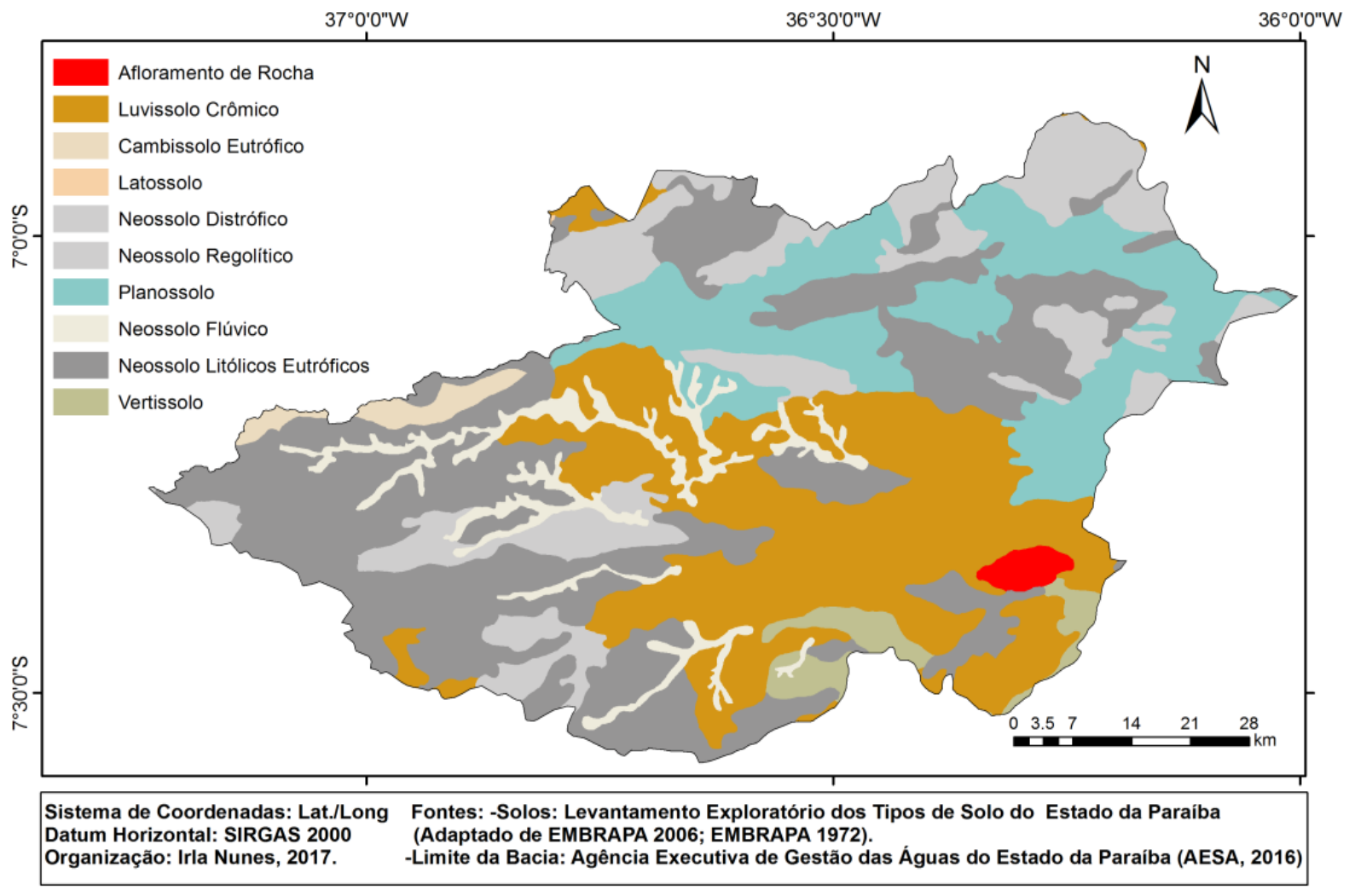

Figura 2 - Tipos de solos existentes na bacia do Rio Taperoá.

\section{Resultados e Discussão}

\section{Análise das mudanças do uso do solo na bacia do Rio Taperoá}

Foram encontrados quatro tipos de classes de uso da terra na bacia do Rio Taperoá (Tabela II), sendo elas as classes de Água, Vegetação Herbácea, Vegetação Arbustiva e Solo Exposto/Agricultura. Analisando a Figura 3, que é a representação do uso e ocupação do solo da bacia espacialmente, existe uma predominância da vegetação herbácea e arbustiva como classes predominantes somando $(82,44 \%)$ do uso da bacia, a classe de solo exposto/agricultura representa $17,25 \%$ da bacia, considerando que as classes de vegetação herbácea e solo exposto/agricultura (somando 71,36\%) são características por ter predominância de capim e vegetação de pastagem e culturas respectivamente, temos com isso, uma grande área que sofre influência antrópica e, assim, risco de erosão.

Tabela II - Associação das classes de uso do solo da bacia do Rio Taperoá com as classes existentes no banco de dados do SWAT

\begin{tabular}{|l|l|l|l|}
\hline Uso do solo & Uso do solo no SWAT & Área (\%) & Área (km²) \\
\hline
\end{tabular}




\begin{tabular}{|c|c|c|c|}
\hline $\begin{array}{l}\text { XVII Simpósio Brasileiro } \\
\text { de Geografia Fisica Aplicada } \\
\text { I Congresso Nacional } \\
\text { de Geografia Física }\end{array}$ & $\begin{array}{l}\text { DA GEOGRAFIA FISICA NA } \\
\text { Instituto de Geociênc } \\
\text { Campinas } \\
28 \text { de Junho à } 02 \text { de }\end{array}$ & $\begin{array}{l}\text { VTEIRA I } \\
\text { Inicamp } \\
\text { e } 2017\end{array}$ & HECIMENTO \\
\hline Vegetação Herbácea & Range Grass $\square$ RNGE & 54,11 & 3062,9 \\
\hline Vegetação Arbustiva & Range Brush $\square$ RNGB & 28,33 & 1616,1 \\
\hline Solo exposto/Agricultura & Barren $\square$ BARR & 17,25 & 976,6 \\
\hline Água & Water $\square$ WATR & $\mathbf{0 , 3 2}$ & 17,4 \\
\hline
\end{tabular}

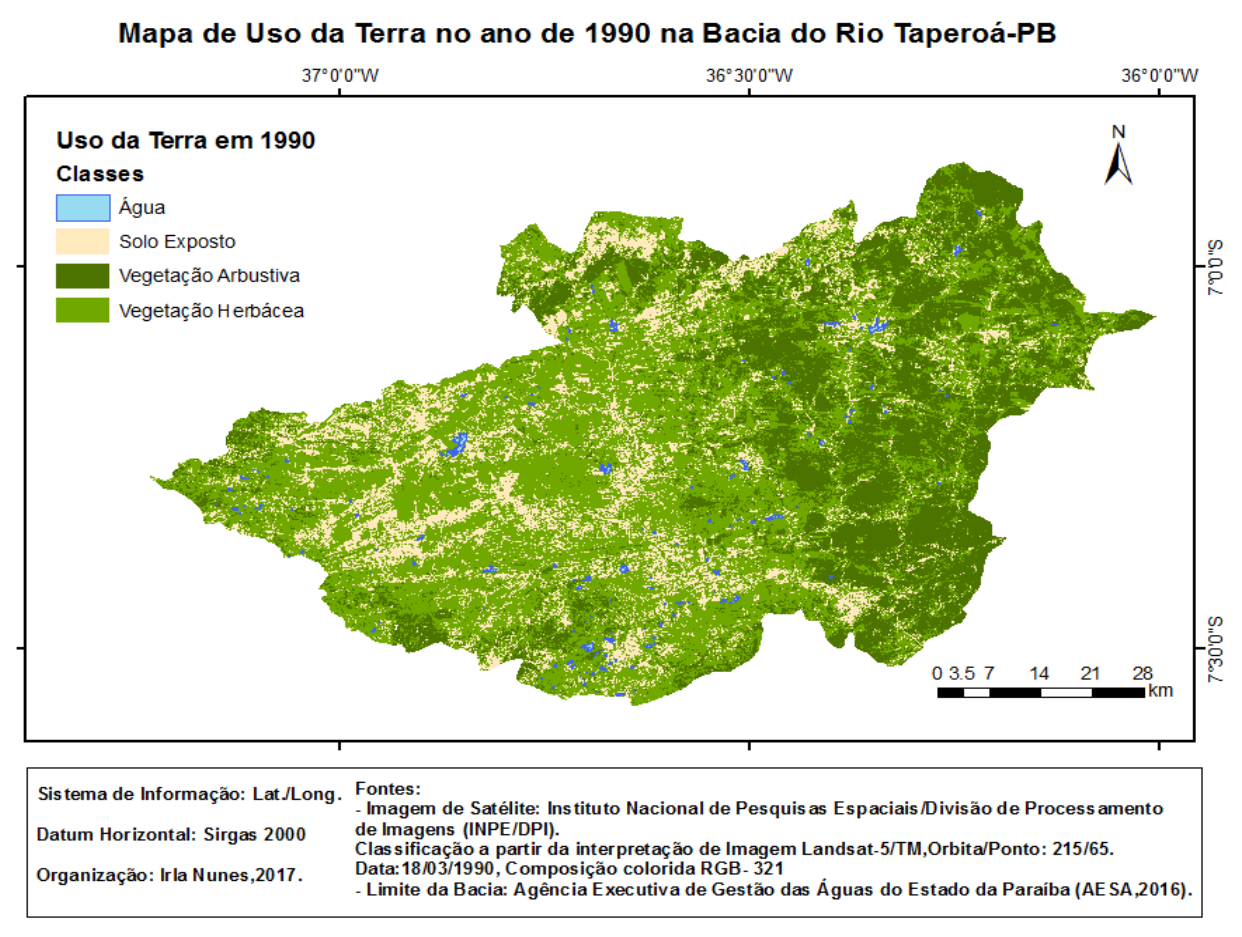

Figura 3 - Classes de uso da Terra da bacia do Rio Taperoá para o ano de 1990

Segundo Paiva et al. (2009), as atividades que mais impactam negativamente a região são: a caprinocultura extensiva, a extração de lenha para a transformação de carvão e a exploração de vários tipos de minérios. Com isso, essas atividades estão aos poucos causando degradação da estrutura superficial da paisagem dessa região. Contribuindo para o desmatamento da vegetação nativa, deixando o solo exposto a fenômenos naturais como chuva, vento e luz solar.

\section{Estimativa do escoamento superficial}

Quanto à estimativa de escoamento superficial a maior concentração do escoamento superficial ocorreu na porção sul da bacia, principalmente nas sub-bacias próximas ao exutório (sub-bacias 9,11, 12 e 15), como pode ser visto na Figura 4, sendo que, a sub-bacia 15 foi aquela com a maior média anual do período estudado e a menor média foi obtida para a sub-bacia 2. Nessa mesma figura ainda é 


\section{OS DESAFIOS DA GEOGRAFIA FÍSICA NA FRONTEIRA DO CONHECIMENTO \\ Instituto de Geociências - Unicamp \\ Campinas - SP \\ 28 de Junho à 02 de Julho de 2017}

possível observar a distribuição espacial do escoamento superficial para cada sub-bacia, com base no uso do solo para o ano de 1990.

Escoamento Superficial Simulado com base no Uso do Solo de 1990

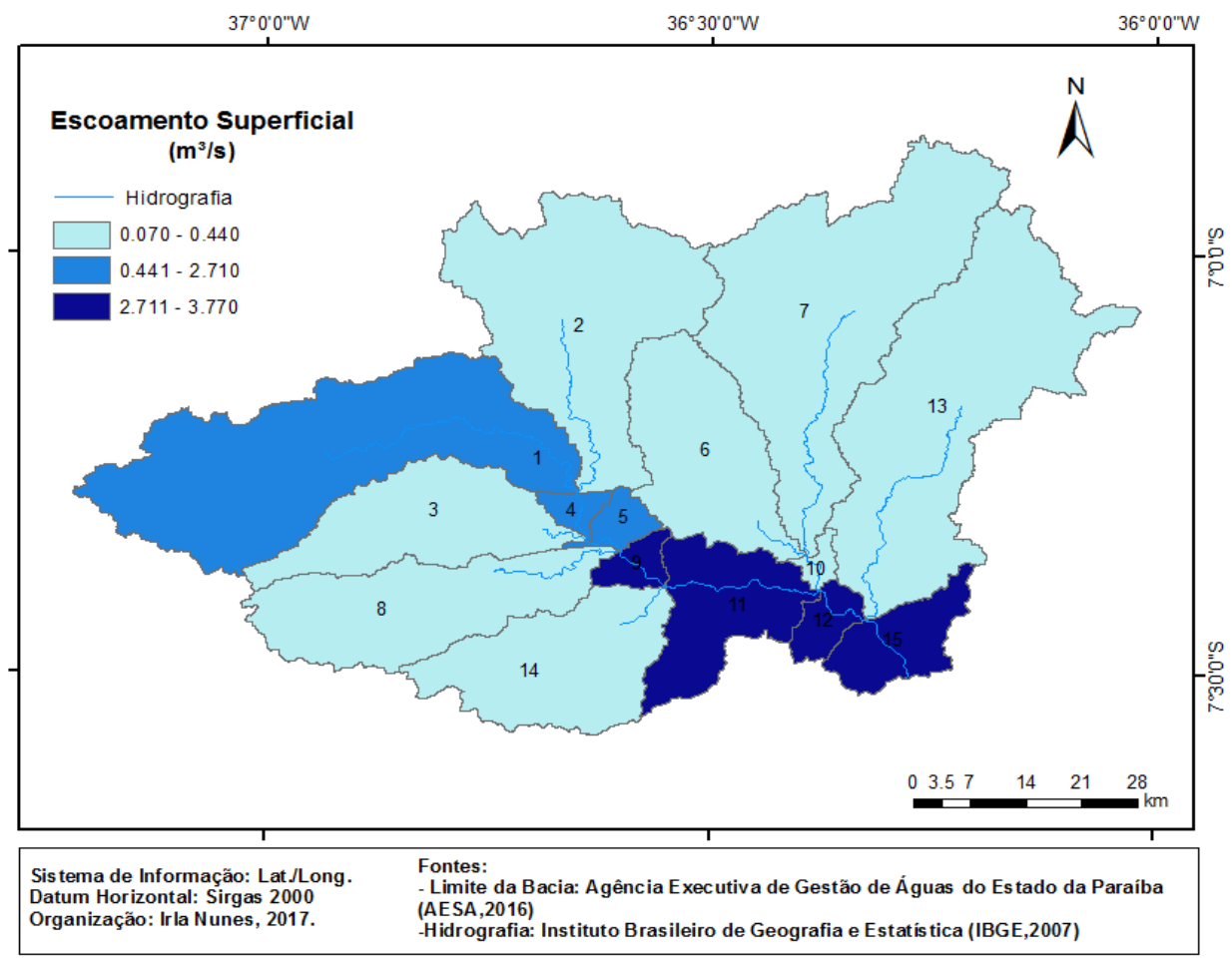

Figura 4 - Distribuição espacial do escoamento superficial na bacia do Rio Taperoá com base no uso do solo de 1990.

Devido à variabilidade das chuvas na região, não é encontrado regularmente grande taxas de vazão, podendo ser até igual a zero em alguns dias. Os valores baixos de escoamento devem ser devido aos solos predominantes, como o Luvissolo Crômico, que não tem como característica um bom escoamento. Com a diminuição da área vegetal, houve a influência na diminuição do processo de infiltraçã ser reduzidos com a presença de vegetação nativas/renascidas e até mesmo as culturas, prevenindo o de água no solo, provocando o aumento do escoamento em algumas áreas, a vegetação ajuda a água a infiltrar, a ausência da mesma provoca a intensificação do deflúvio, como confirma Aragão et al. (2011), quando diz que o escoamento superficial e o impacto das gotas de chuva no solo, podem o solo da erosão e aumentando a infiltração.

\section{Estimativa de produção de sedimentos}

Quanto à estimativa da produção de sedimentos (Figura 5), pode-se observar que, as sub-bacias 1, 3 e 8 foram as que mais produziram sedimentos, e estão localizadas na porção oeste da bacia, sendo que a 


\section{OS DESAFIOS DA GEOGRAFIA FÍSICA NA FRONTEIRA DO CONHECIMENTO Instituto de Geociências - Unicamp \\ Campinas - SP \\ 28 de Junho à 02 de Julho de 2017}

maior produção anual ocorreu na sub-bacia 8 (0,08 t/ha/ano). Esse fato pode ser explicado, devido ao fato dessa porção (oeste da bacia) apresentar áreas de solo exposto e vegetação herbácea, ou seja, uma área com intenso uso do solo, podendo haver mais produção de sedimentos. A média anual da bacia foi de $0,006 \mathrm{t} / \mathrm{ha} / \mathrm{ano}$.

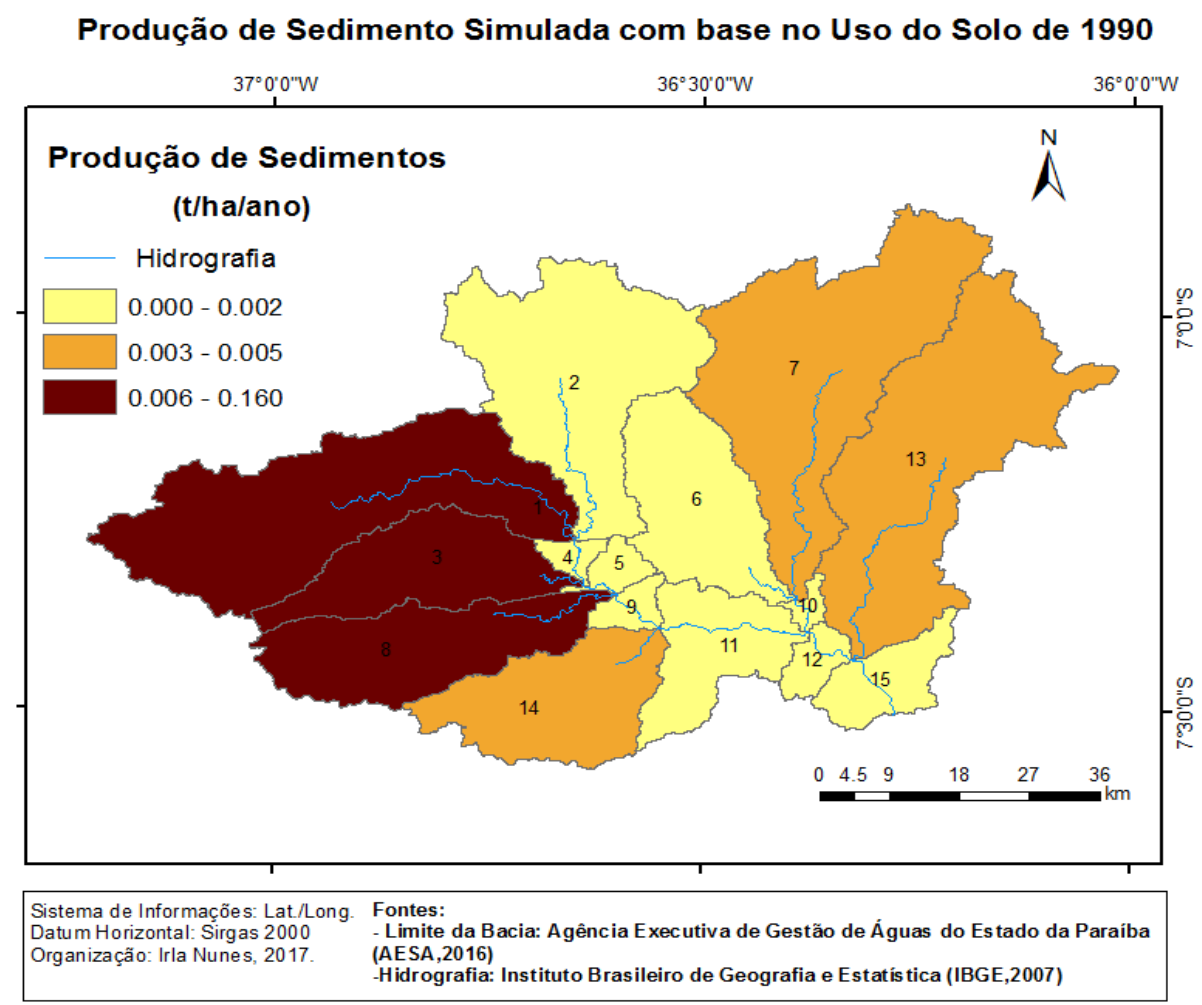

Figura 5- Distribuição espacial da produção de sedimentos na bacia do Rio Taperoá com base no uso do solo do ano de 1990

O tipo do uso do solo da bacia pode ter influenciado a produção de sedimentos em algumas áreas, como as mais desmatadas e com pouca vegetação. Como afirma Araújo e Knight (2005) ao dizer que o desmatamento também contribui para o aumento do escoamento superficial e da produção de sedimentos, com perda de nutrientes e redução da capacidade produtiva dos solos, acarretando o assoreamento de reservatórios e rios (BERTONI e LOMBARDI NETO, 2005).

Na porção oeste da bacia também é onde estão localizadas as áreas de cabeceira com maior declive e áreas de alto declive influenciam no processo erosivo, aumentando a produção de sedimento. Como confirma Vilella e Matos (1975) ao afirmar que o grau de declividade de um terreno pode controlar a velocidade do deslocamento da água no escoamento superficial e quanto maior a velocidade, maior será a força erosiva, contribuindo para uma maior produção de sedimento. 


\section{Considerações Finais}

Pode-se concluir que as sub-bacias que apresentaram o maior escoamento superficial estão localizadas na porção sul da bacia em decorrência dessa região possuir as maiores declividades da bacia. No que tange a estimativa da produção de sedimentos, notou-se que as sub-bacias localizadas na porção oeste da bacia, que apresentam solo exposto e vegetação herbácea, são aqueles locais com maior produção de sedimentos. Face ao exposto, conclui-se que o uso da terra e a declividade são atores preponderantes para a ocorrência dos maiores valores de escoamento superficial e produção de sedimentos, pois possuem grande influência na distribuição espacial desses processos na bacia do Rio Taperoá, ou seja, quanto ao comportamento da bacia, ocorreu o que era esperado para regiões semiáridas do Brasil. Com os resultados obtidos, foi possível através desta pesquisa entender a importância dessa temática em áreas semiáridas, a fim de obter o melhor entendimento da dinâmica desses processos na região.

\section{REFERÊNCIAS}

ANDRADE, R. L.; SOUTO, J. S.; SOUTO, P.C.; BEZERRA, D. M. 2008. Deposição de serapilheira em área de caatinga na RPPN “Fazenda Tamanduá”, Santa Terezinha-PB, Caatinga, v. 21, n.2, p 223-230.

ARAGÃO, R.; ALMEIDA, J.A. P.; FIGUEIREDO, E.E.; SRINIVASAN, V.S. Mapeamento do potencial de erosão laminar na bacia do rio Japaratuba - SE, via SIG. Revista Brasileira de Engenharia Agrícola e Ambiental, 15:731-740, 2011

ARAÚJO, J.C.; KNIGHT, D.W.A review of the measurement of sediment yield in different scales. Revista Escola de Minas, v. 53, n. 3, p. 257-265, 2005.

ARNOLD, J.G. \& ALLEN, P.M. Estimating hydrologic budgets for three Illinois watersheds. Journal of Hydrology, v. 176, p. 57-77, 1996.

BAKKER. M. M.; GOVERS, G.; KOSMAS, C.; VAN ACKER, V.; VAN OOST, K.; ROUNSEVELL, M. Soil erosion as a driver of land-use change, Agriculture, Ecosystems \& Environment. v 105, p.467-481, 2005.

BAKKER. M. M; GOVERS, G; ROUNSEVELL, M. D. A. The crop productivity- erosion relationship: an analysis based on experimental work. Catena, v. 57, p.55-76, 2004.

BERTONI, J.; LOMBARDI NETO, F. Conservação do solo. 5. ed. São Paulo, Ícone, 2005. 355p.

CARVALHO, N. O. Hidrossedimentologia prática. Rio de Janeiro: Editora Interciência, 2008. 326p.

CERDAN, O.; GOVERS, G.; LE BISSONNAIS, Y. Rates and spatial variations of soil erosion in Europe: A study based an erosion plot data. Geomorphology, v. 122, p. 167-177, 2010. 
DANTAS, J. C.; SILVA, M. A.; SILVA, R. M.; VIANNA, P. C. G. Erosão usando o modelo SWAT para uma $\square$ simulação vazão grande bacia da região semiárida da Paraíba. Geociências, v. 34, n. 4, p.816-827, 2015.

DESIR, G; MARÍN, C. Factors controlling the erosion rates in a semi-arid zone (Bardenas Reales, NE Spain). Catena, V. 71, p.31-40, 2007.

EMPRESA BRASILEIRA DE PESQUISA AGROPECUÁRIA - EMBRAPA, Serviço Nacional de Levantamento e Conservação de Solos (Rio de Janeiro, RJ). Súmula da X Reunião Técnica de Levantamento de Solos (SNLCS, Miscelânea, 1), Rio de Janeiro, RJ: 1979, p. 83

FAO. Desarrollo sostenible de tierras aridas y lucha contra La desertificacion: Posición de la FAO. Rome, 1993. 30p.

MENDONÇA, F. \& DANNI-OLIVEIRA, I.M. Climatologia: noções básicas e climas do Brasil. São Paulo: Oficina de Textos, 2007, 206p.

PAIVA, L. A. N.; SILVA, F. M.; NASCIMENTO, P. S.R. Uso de imagens MODIS e TM para a detecção de áreas degradadas na sub-bacia do Taperoá- PB. In: SIMPÓSIO BRASILEIRO DE GEOGRAFIA FÍSICA APLICADA, 13, 2009, Anais..., Viçosa: UFV, 2009.

PEREZ-MARIN, A. M.; CAVAlCANTE, A. M. B.; MEDEIROS, S. S.; TINOCO, L. B. M.; SALCEDO, I. H. Núcleos de desertificação no semiárido brasileiro: Ocorrência natural ou antrópica? Parcerias Estratégicas, v.17, p.87-106, 2012.

SILVA, J.V; ALECRIM, M. A. B; SILVA, D. O; COSTA, C.C; OLIVEIRA, R.J. DE. Perdas de Solo e água por Erosão Hídrica em Floresta Equiânea em um Latossolo Vermelho-Amarelo. Revista Brasileira de Ciência Agrária, v.5, n.4, p.579-584, 2010.

SILVA, R.M.; SANTOS, C.A.G.; SILVA, A.M. Predicting soil erosion and sediment yield in the Tapacurá catchment, Brazil. Journal of Urban and Environmental Engineering, v. 8, p. p. 75-82, 2014.

SILVA, R. M.; SANTOS, C. A. G.; SILVA, V. C. L.; SILVA, L.P. (2013). Erosivity, surface runoff, and soil erosion estimation using GIS-coupled runoff-erosion model in the Mamuaba catchment, Brazil. Environmental Monitoring and Assessment, v. 185, n. 8, p. 8977-8990.

SOUZA, B. I.; SILANS, A. M. B. P.; SANTOS, J. B. Contribuição ao estudo da desertificação na Bacia do Taperoá. Revista Brasileira de Engenharia Agrícola e Ambiental, v.8 n2/3, p.292-298, 2004;

SOUSA, R.F.; BARBOSA, M.P.; MORAIS NETO, J.M.; FERNANDES, M.F. Estudo do processo da desertificação e das vulnerabilidades do Município de Cabaceiras-Paraíba. Revista Brasileira de Engenharia Ambiental, v.4, n.1, p.89-102, 2007. 
VILLELA, S. M.; MATOS, A. Hidrografia Aplicada. São Paulo: Mc Graw-Hill do Brasil, 1975.

WILLIAMS, J. R. Sediment-yield prediction with universal equation using runoff energy factor, In: Present and Prospective Technology for Predicting Sediment Yield and Sources. Washington D.C.: USDA, 1975, pp. 244-252. 